\title{
Biological Significance of Glutamate Signaling during Digestion of Food through the Gut-Brain Axis
}

\author{
Akihiko Kitamura Tomokazu Tsurugizawa Kunio Torii \\ Nutritional Physiology Fundamental Research Group, Frontier Research Laboratories, Institute for Innovation, \\ Ajinomoto Co., Inc., Kawasaki, Japan
}

\section{Key Words}

Monosodium L-glutamate $\cdot$ Autonomic reflex .

Postingestive effect $\cdot$ Vagus nerve $\cdot$ Functional magnetic resonance imaging

\begin{abstract}
Monosodium L-glutamate (MSG) elicits a unique taste termed umami and is widely used as a flavor enhancer in various cuisines. In addition, recent studies suggest the existence of sensors for L-glutamate (Glu) and transduction molecules in the gut mucosa as well as in the oral cavity. The vagal gastric afferent responds specifically to the luminal stimulation of Glu in the stomach and regulates the autonomic reflexes. The intragastric infusion of Glu also activates several brain areas (insular cortex, limbic system, and hypothalamus) and is able to induce flavor-preference learning in rats. These results suggest that umami signaling via gustatory and visceral pathways plays an important role in the processes of digestion, absorption, metabolism, and other physiological functions via activation of the brain.
\end{abstract}

Copyright $\odot 2011$ S. Karger AG, Basel
(C) 2011 S. Karger AG, Basel

0012-2823/11/0835-0037\$38.00/0

Accessible online at:

www.karger.com/dig

\section{Introduction}

L-Glutamate (Glu) is an amino acid with multiple functions in our body. As an essential substrate in the intermediary metabolism, free Glu is present in most organs and tissues (skeletal muscles, brain, kidneys, and liver) in substantial concentrations $[1,2]$. Glu plays an important role in the energy metabolism and in the synthesis of other amino acids, glutathione, and proteins. In the brain, Glu acts as a major excitatory neurotransmitter, and its activity regulates synaptic plasticity, learning, memory, motor activity, and neural development. In the oral cavity, Glu in foods elicits unique taste termed umami, which is generally thought to be a signal for protein ingestion.

In addition to the gustatory roles of Glu, recent studies have unveiled the postingestive significance of Glu on various physiological functions such as digestion, $\mathrm{ab}$ sorption, metabolism, and energy homeostasis through brain activation. These effects might be mediated via gut Glu sensors functionally linked to the afferent branches of the vagus nerve, or via the afferent sensory nerves in the oral cavity. Moreover, Glu acts as a reinforcer after ingestion via vagal afferent activation in the gut. For example, we recently observed that an intragas- 


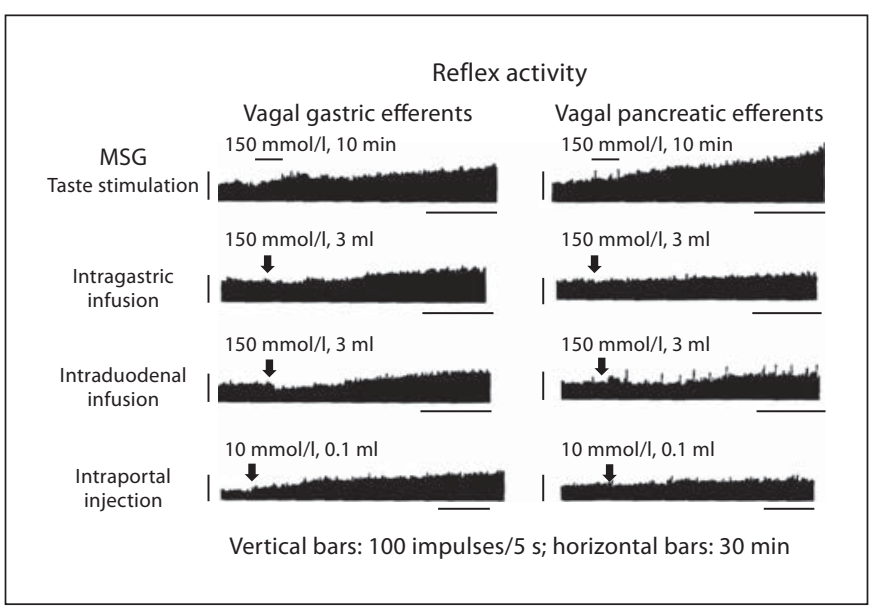

Fig. 1. Effect of reflex activation of vagal gastric and pancreatic nerve activity from oral, gastric, intestinal and hepatoportal glutamate sensors. Reproduced from Niijima [17].

tric infusion of Glu induced conditioned flavor preference in rats $[3,4]$.

Here, we describe the physiological significance of dietary Glu for the maintenance of body homeostasis from the point of view of autonomic reflexes. We also describe the positive postingestive effects of several nutrients, primarily Glu, sugar, and lipids, with regard to behavior and brain function.

\section{Gustatory Stimuli Regulate Autonomic Nerve Activity}

Taste sensations affect various visceral efferent nerve activities and functions. Salivary secretion is well known to be one of the taste-induced autonomic reflexes [5]. The relative strengths of different stimuli inducing parotid salivary flow are as follows: citric acid (sour) $>$ monosodium Glu (MSG; umami) > $\mathrm{NaCl}$ (salty) $>$ sucrose (sweet) $\geq$ magnesium sulfate (bitter) [6]. The role of saliva is not only to lubricate food for swallowing but also to initiate the digestion of starch and fats because it contains the enzymes amylase and lipase. In addition, there are various reports describing other taste-induced reflexes. Sweet taste stimulation with sucrose and glucose solution increases the efferent activity of the pancreatic and the hepatic vagus nerves in rats, whereas a salty taste solution containing a high concentration of $\mathrm{NaCl}$ suppresses such activity [7-10]. In addition, sweet taste stimulation elicits insulin release prior to increasing plasma glucose levels, a process called cephalic-phase insulin release [11-13]. By contrast, sweet taste stimulation was observed to suppress vagal gastric efferent (VGE) activity and the efferent activity of the adrenal, pancreatic, and hepatic sympathetic nerves, whereas salty taste stimulation was shown to increase these activities $[9,14]$. Moreover, sweet taste signals stimulate gastric acid secretion via the vagus nerve [15]. Umami taste stimulation produced by an MSG solution was able to activate VGE activity and the efferent activity of the pancreatic and hepatic vagus nerves (fig. 1) $[10,16,17]$, in association with an increase in insulin secretion [18]. However, it has been reported that MSG does not elicit cephalic-phase insulin release [19], so further study will be necessary. Altogether, taste sensation induces the reflexes production of salivary, gastric, and insulin secretions, which are important for metabolism and the digestion and absorption of food.

\section{Gut Nutrient Stimuli Regulate Autonomic Nervous System Activity}

In the gastrointestinal (GI) tract, various nutrients are detected and absorbed through the luminal mucosa. $\mathrm{Nu}-$ trients also regulate the activity of vagal afferent nerves and the release of GI peptides, including cholecystokinin (CCK), peptide YY, glucagon-like peptide-1 (GLP-1), leptin, ghrelin, and others [20-23].

It was thought for a long time that the vagal gastric afferents (VGA) in the stomach could detect only gastric distension and not individual nutrients. However, we have previously reported that Glu evoked visceral sensations in the stomach [17]. This report is important in the field of gastric nutrient perception because these data strongly suggest that chemical perception, in particular an amino acid-sensing system, exists in the gastric mucosa. Interestingly, among the 20 amino acids, only Glu stimulates the rat VGA (fig. 2) [24]. Luminal perfusion with the local anesthetic lidocaine abolished the Glu-evoked VGA activation, indicating that this response is a chemical event within the gastric mucosa. Furthermore, the Glu response was blocked by depletion of serotonin (5-HT) and by inhibition of $5-\mathrm{HT}_{3}$ receptors or the nitric oxide (NO) synthase enzyme. The afferent response was also mimicked by luminal perfusion or intravenous injection with the NO donor sodium nitroprusside. In addition, NO donorinduced afferent activation was abolished by $5-\mathrm{HT}_{3}$ receptor blockage or depletion of 5-HT [24, 25]. This finding strongly supports the possibility of intercellular communication in the rat gastric mucosa between mucosal cells 
and the vagus nerve using NO and 5-HT. More than $90 \%$ of 5-HT throughout the body is localized in the enterochromaffin cells of the GI mucosa. The physiological role of mucosal 5-HT released from enterochromaffin cells serves a paracrine function by specifically recognizing Glu in the lumen of the stomach, which is similar to the role reported in duodenal glucose sensing.

Our understanding of the sensing of nutrients by the gut is based on the 'intestinal sensor cell hypothesis' originally proposed in the 1970s by Fujita et al. [26]. This hypothesis states that nutrient-sensing cells are distributed in the gastric antrum or duodenal mucosa and that when these cells interact with luminal nutrients, they release hormones in an endocrine or paracrine manner to transfer information about luminal nutrient content to other organs, including the brain, via endocrine or vagal pathways. However, the cells involved in gut nutrient perception remained unidentified for a long time. In 1996, Höfer et al. [27] reported that taste-like cells similar to the taste cells in the oral cavity are distributed in the gastric and intestinal mucosa and they proposed that these taste-like cells represent the unknown sensor cells. Subsequently, with the development of molecular biology techniques in the field of taste research, several taste receptors that sense amino acids have been identified. We now know that metabotropic Glu receptors (mGluRs), a calciumsensing receptor (CaSR), and a taste receptor (the T1R1/ T1R3 complex) are all linked to amino acid sensation in the tongue. These receptors are also candidates for luminal amino acid sensors. Although the molecule that senses Glu in the gastric mucosa is still unknown, intragastric infusion of MSG causes a vago-vagal reflex, which increases VGE, as well as vagal pancreatic and celiac efferent activities (fig. 1) [17,28]. Interestingly, inosine monophosphate, which is another umami substance, also activates VGA and increases vagal celiac efferent activity [28]. Assuming there is a universal coexistence of free Glu with dietary protein, these findings suggest that a Glusensing system in the stomach could contribute to the gastric phase of protein digestion and could integrate nutrient information in the brain.

In contrast to what occurs in the small intestine, there are many reports that intraduodenal infusion of amino acids or oligopeptides alters vagal celiac afferent (VCA) activity. Sharma and Nasset [29] observed an apparent increase in mesenteric afferent activity in either wholenerve or multifiber preparations from the GI tract following amino acid infusions in cats. Using a unitary recording technique in the nodose ganglion, Jeanningros and colleagues $[30,31]$ subsequently revealed in detail the re-

Glutamate Signaling during Digestion of Food through the Gut-Brain Axis

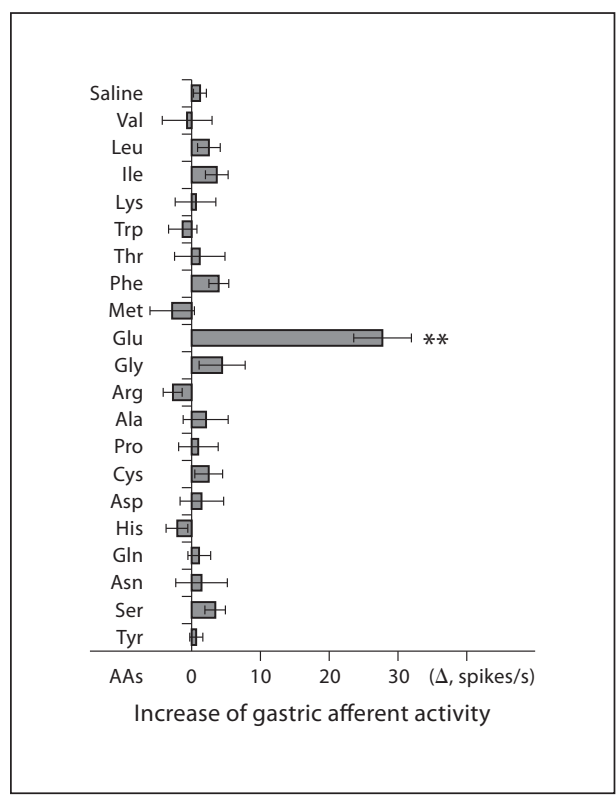

Fig. 2. VGA responses to intragastric infusion of various amino acids. Each aqueous solution $(150 \mathrm{mmol} / \mathrm{l}, 2 \mathrm{ml})$ was introduced into the rat stomach, and the mean discharge rate above baseline at 20 min was plotted. Each column and horizontal bar represents mean \pm SEM from 5 rats. ${ }^{* *} \mathrm{p}<0.05$ vs. saline (Kruskal-Wallis test). Reproduced from Uneyama et al. [24].

sponse of VCA to amino acid infusions in the cat small intestine. Their report described many sensors responsive to arginine, leucine, and other amino acids. Recently, we re-examined the luminal amino acid sensitivity of VCA in rats. Intraintestinal infusion of MSG, lysine, leucine, and other amino acids evoked excitatory responses in VCA [32]. In contrast to these amino acids, intraintestinal infusion of glycine, methionine, and certain other amino acids led to the depression of afferent nerve activity [32]. In rats, duodenal infusions of protein hydrolysates also increased mesenteric afferent activity $[33,34]$. Schwartz and Moran [34] revealed that duodenal protein hydrolysates (e.g. peptone) stimulated vagal celiac afferents, indicating that an amino acid sensor or oligopeptide sensor might exist in the rat duodenum. However, the mechanisms underlying such sensations are not fully understood, and further research will be needed.

Changes in VCA activity induce autonomic reflexes and regulate visceral functions. Intraintestinal infusions of MSG resulted in an increase in VGE, vagal pancreatic efferent activity [16, 17], and lysine evoked long-lasting enhancement of VGE activity [32]. On the other hand, the intraintestinal infusion of glycine inhibited VGE activity 


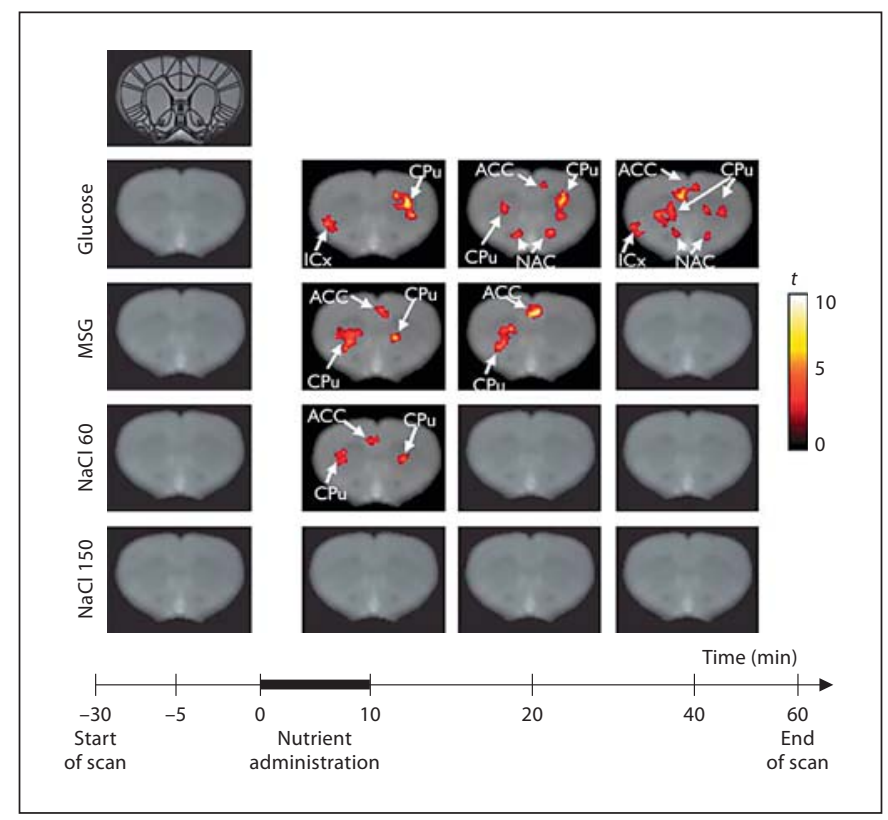

Fig. 3. Activated area of the rat forebrain specific to post-oral nutrients (glucose, MSG, $\mathrm{NaCl} 60$ and $\mathrm{NaCl} 150$ ) compared with common control images which are averaged during $10 \mathrm{~min}$ before administration. T-map images (bregma +2.0 ) depict activated brain regions at pre-administration $(-5 \mathrm{~min})$ and 10,20 , and 40 min after the start of intragastric infusion. Upper figure is a template image overlaid with Paxinos Atlas. ACC = Anterior cingulate cortex; $\mathrm{CPu}=$ caudate putamen; $\mathrm{ICx}=$ insular cortex; $\mathrm{NAC}=$ nucleus accumbens. Color bar, t-value. Reproduced from Tsurugizawa et al. [38].

[32]. In addition, introduction of a glucose solution into the intestine increased VCA activity; the sensing mechanism underlying glucose effects has been described in another review [35]. Glucose solution also suppressed sympathetic adrenal efferent activity and enhanced vagal pancreatic efferent activity [32]. These observations support the hypothesis that vagal GI afferent signals regulate GI motility, metabolic activity, and food intake [36, 37].

\section{Brain Activation by Gut Nutrient Stimulation}

From recent studies, in addition to the autonomic reflex, we can understand that the effects of ingested nutrients are processed in the forebrain to determine the next feeding behavior. To investigate which regions of the rat brain respond to ingested nutrients, we used a functional magnetic resonance imaging (fMRI) technique. The merit of fMRI is that activated areas in the whole brain can be investigated simultaneously. An intragastric load of $60 \mathrm{mM}$ MSG or isocaloric $(60 \mathrm{~mm})$ glucose solution has been shown to activate distinct forebrain regions (fig. 3) $[38,39]$. An intragastric load of MSG significantly activated several brain regions including the amygdala, lateral hypothalamus, dorsomedial hypothalamus, and the medial preoptic area. On the other hand, an intragastric infusion of glucose activated the insular cortex, amygdala, nucleus accumbens (which is the terminal of the dopaminergic projection), and the lateral and ventromedial hypothalamus. We also investigated brain responses to an intragastric load of corn oil emulsion, which activated the amygdala, lateral hypothalamus, hippocampus, and the ventral tegmental area [40].

Behavioral studies also showed that ingested Glu, glucose, and corn oil emulsion have positive postingestive effects with regard to flavor preferences in rats $[3,41,42]$. In rodents and humans, the preference for the flavor of an ingested solution can be increased by repeatedly pairing it with ingestion or intragastric infusion of a nutrient solution. This paradigm is called conditioned flavor preference (CFP). Behavioral studies revealed that the intragastric infusion of carbohydrates, lipids, and alcohols induces CFP in rodents [41-43]. In addition, we previously showed that an intragastric load of $60 \mathrm{mM}$ MSG evoked CFP in rats. Isocaloric $(60 \mathrm{mM})$ glucose and isotonic $(60$ $\mathrm{mM}) \mathrm{NaCl}$ solution did not evoke CFP (fig. 4) [3, 4], although $480 \mathrm{~mm}$ glucose solution did evoke CFP. Much higher concentrations of glucose lead to an increase in blood glucose and insulin. These results indicate that the preference for the flavored solution paired with a gut infusion of MSG is due to neither a caloric effect nor an osmotic effect. Based on the results of functional brain imaging and CFP studies, the brain regions commonly activated in response to the intragastric infusion of Glu, glucose, and corn oil emulsion include the anterior cingulate cortex, insular cortex, amygdala, caudate putamen, hippocampus, and the lateral hypothalamus [39, 40]. Thus, these regions should be related to CFP. In particular, the lateral hypothalamus is an important area for food or liquid intake. A previous report revealed that lesions of the lateral hypothalamus diminished CFP induced by intragastric infusion of glucose [44]. The glucose-sensitive neurons that exist in the ventromedial hypothalamus are activated as the intracellular glucose levels increase. The dopaminergic projections from the ventral tegmental area to the nucleus accumbens, amygdala, and the lateral hypothalamus are related to the preference for or addiction to ingested glucose and corn oil. Some studies showed that sugar intake increased dopamine release in the nucleus accumbens shell region in 


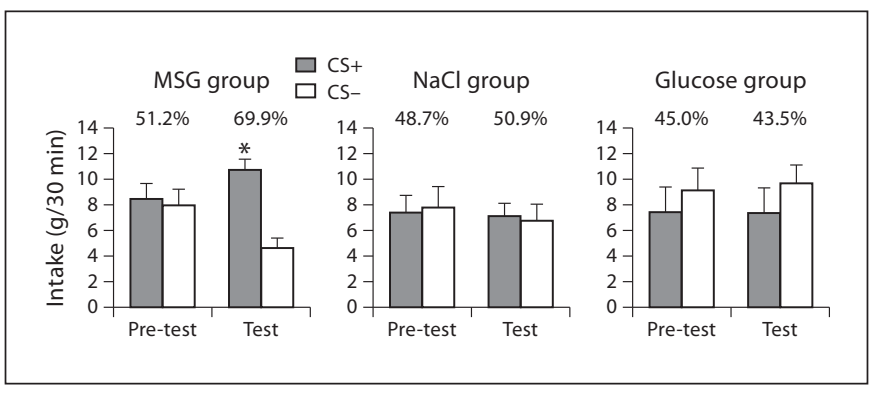

Fig. 4. Mean intake of CS+ (flavored water with intragastric infusion of MSG, $\mathrm{NaCl}$, or glucose) and CS- (flavored water with intragastric infusion of water) solutions in the pre-test and test periods. Mean percent intakes of the $\mathrm{CS}+$ solution are shown above the bars. Reproduced from Uematsu et al. [3].

rats, causing them to become addicted to all sugars [45]. On the other hand, intragastric infusion of Glu does not activate the nucleus accumbens (fig. 3), and lesions of neurons in the ventral tegmental area do not affect the preference for Glu in rats [46]. These results show that the postingestive effects of Glu differ from those of sugar and lipids.

Another advantage of fMRI is that it has better temporal resolution than an alternative monitoring technique, $\mathrm{c}$-fos labeling. The time course of brain activation is different for Glu and for glucose, as revealed by fMRI (fig. 5) [38]. An intragastric infusion of $60 \mathrm{~mm}$ Glu induced activation in most of the brain during the infusion period. In contrast, intragastric infusion of $60 \mathrm{mM}$ glucose induces long-term activation lasting more than $1 \mathrm{~h}$. These different temporal and regional activation patterns in the brain are due to distinctive signaling pathways between the gut and the brain and they result in distinctive effects on postingestive behavioral modulation.

\section{Signaling Mechanisms of the Gut-Brain Axis}

Ingested nutrients are digested and absorbed in the GI tract. The afferent vagus nerve, which innervates the entire GI tract and projects to the nucleus of the solitary tract (NTS), is then activated, or peripheral humoral factors such as insulin and GLP-1 are released. In addition to absorption and metabolism in the gut, recent studies have indicated that the stomach, duodenum, and intestine contain chemosensing taste receptors and other Gprotein-coupled receptors (GPRs). The T1R receptors, which are responsible for the chemoreception of the sweet

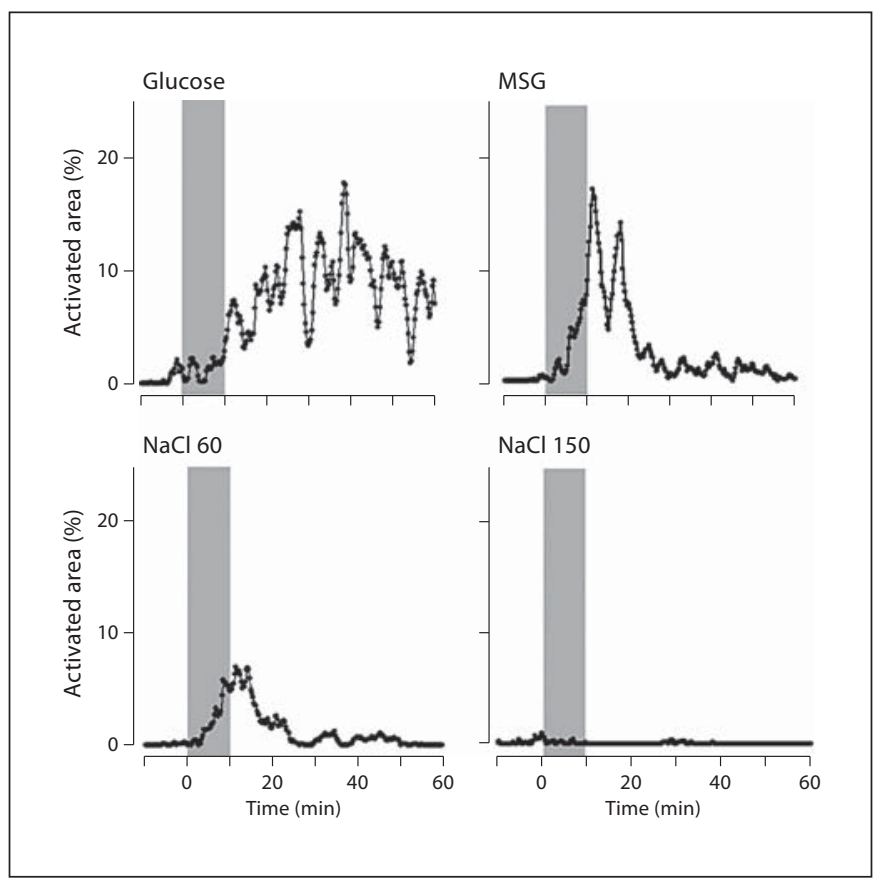

Fig. 5. Time course of the percent changes in significantly activated area in rats. Horizontal axis is elapsed time after the start of infusion. Reproduced from Tsurugizawa et al. [38].

and umami tastes, and the family of $\mathrm{T} 2 \mathrm{R}$ receptors, which mediate the chemoreception of the bitter taste, are both expressed in the gut $[47,48]$. A GPR120 exists in both the oral cavity and the GI tract, and free fatty acids interact with it to induce the release of circulating GLP-1 [49]. Free fatty acids also interact with GPR40 in the GI tract and promote the secretion of GLP-1 [50] and CCK [51]. GLP-1 and CCK evoke c-fos positive immunoreactivity in several brain regions, including the amygdala [52-54]. Intragastric infusion of glucose solution increases blood glucose, GLP-1, and insulin. Circulating GLP-1 acts on neurons in the NTS. Recently, we demonstrated that fluctuations in insulin following the intragastric administration of glucose correlate with fMRI responses in the amygdala, ventromedial hypothalamus, and nucleus accumbens [39].

Electrophysiological studies have shown that intragastric and enteric delivery of amino acids and lipids both activate the afferent vagus nerve as described above [31$33,55,56]$. The intraportal administration of amino acids also activates the afferent vagus nerve [57]. These reports indicate that the afferent vagus nerve is important for the transmission of gut nutrient information to the brain. Interestingly, behavioral studies have shown that abdomi- 
nal vagotomy eliminates CFP in response to intragastric infusion of Glu [4] but does not affect CFP response to intragastric infusion of carbohydrates in rats [58]. An fMRI study showed that total and abdominal vagotomy diminished Glu-induced activation in the NTS and hypothalamus, whereas total vagotomy did not affect glucose-induced brain activation [39]. Instead, brain activation correlated with fluctuations in insulin following intragastric glucose infusion [39]. These results from fMRI studies of vagotomized rats are consistent with postingestive behavior studies, indicating that internal signals in response to Glu mainly involve the vagus nerve, whereas those in response to glucose at least partly involve insulin.

Finally, there are distinct postingestive effects in response to different nutrients, resulting in the activation of forebrain regions. The spatial and temporal patterns of brain activation could link postingestive behavioral and physiological effects.

\section{Conclusions}

Glu plays an important role in the perception of the umami taste, intermediary metabolism, and excitatory neurotransmission. In one series of studies, we showed that dietary Glu also stimulates Glu sensors in the stomach and intestines, producing local effects on gut function. Moreover, via the release of signaling molecules NO and 5-HT, the presence of Glu in the gut leads to the activation of the vagal afferent nerve and, consequently, of a number of target areas in the brain. In addition, we described the postingestive effects of Glu compared to those of glucose and lipids. Previous fMRI and behavioral studies in rodents have indicated that Glu has positive postingestive effects through the vagal afferent nerve, but no reinforcing properties. Altogether, these findings indicate that dietary Glu influences numerous physiological functions, suggesting a broad, integrative role for dietary Glu in body homeostasis.

\section{Acknowledgement}

We thank Dr. Gary K. Beauchamp (Monell Chemical Senses Center, Philadelphia, Pa., USA) for the valuable comments on the manuscript.

\section{Disclosure Statement}

No conflicts of interest to disclose.

\section{References}

1 Giacometti T: Free and bound glutamate in natural products; in Filer LJ Jr, Garattini MR, Kare MR, Reynolds WA, Wurtman RJ (eds): Glutamic Acid: Advances in Biochemistry and Physiology. New York, Raven Press, 1979, pp 25-34.

2 Young VR, Ajami AM: Glutamate: an amino acid of particular distinction. J Nutr 2000; 130:892S-900S.

- 3 Uematsu A, Tsurugizawa T, Kondoh T, Torii $\mathrm{K}$ : Conditioned flavor preference learning by intragastric administration of L-glutamate in rats. Neurosci Lett 2009;451:190-193.

-4 Uematsu A, Tsurugizawa T, Uneyama H, Torii K: Brain-gut communication via vagus nerve modulates conditioned flavor preference. Eur J Neurosci 2010;31:1136-1143.

5 Hector MP: Reflexes of salivary secretion; in Garrett JR, Ekström J, Anderson LC (eds): Neural Mechanisms of Salivary Gland Secretion. Basel, Karger, 1999, pp 196-217.

-6 Hodson NA, Linden RA: The effect of monosodium glutamate on parotid salivary flow in comparison to the response to representatives of the other four basic tastes. Physiol Behav 2006;89:711-717.
7 Niijima A: Control of liver function and neuroendocrine regulation of blood glucose levels; in Brooks CMcC, Koizumi K, Sato A (eds): Integrative Functions of the Autonomic Nervous System. Tokyo, University of Tokyo Press/Amsterdam, Elsevier/North-Holland Biomedical Press, 1979, pp 68-83.

8 Niijima A: Effects of taste stimulation on the efferent activity of the pancreatic vagus nerve in the rat. Brain Res Bull 1991;26:161164.

-9 Niijima A: Effects of taste stimulation on the efferent activity of the autonomic nerves in the rat. Brain Res Bull 1991;26:165-167.

10 Niijima A: Effect of umami taste stimulations on vagal efferent activity in the rat. Brain Res Bull 1991;27:393-396.

11 Louis-Sylvestre J: Preabsorptive insulin release and hypoglycemia in rats. Am J Physiol 1976;230:56-60.

12 Steffens AB: Influence of the oral cavity on insulin release in the rat. Am J Physiol 1976; 230:1411-1415.

13 Strubbe JH, Steffens AB: Rapid insulin release after ingestion of a meal in the unanesthetized rat. Am J Physiol 1975;229:10191022.
14 Jiang ZY, Niijima A: Effects of taste stimuli on the efferent activity of the gastric vagus nerve in rats. Neurosci Lett 1986;69:42-46.

15 Ikuno H, Sakaguchi T: Gastric vagal functional distribution in the secretion of gastric acid produced by sweet taste. Brain Res Bull 1990;25:429-431.

16 Niijima A: Effects of oral and intestinal stimulation with umami substance on gastric vagus activity. Physiol Behav 1991;49:10251028.

17 Niijima A: Reflex effects of oral, gastrointestinal and hepatoportal glutamate sensors on vagal nerve activity. J Nutr 2000;130:971S973S.

18 Niijima A, Togiyama T, Adachi A: Cephalicphase insulin release induced by taste stimulus of monosodium glutamate (umami taste). Physiol Behav 1990;48:905-908.

19 Tonosaki K, Hori Y, Shimizu Y, Tonosaki K: Relationships between insulin release and taste. Biomed Res 2007;28:79-83.

20 DeFonseka A, Kaunitz J: Gut sensing mechanisms. Curr Gastroenterol Rep 2009;11:442447. 
21 Kitamura A, Niijima A, Torii K, Uneyama H: Amino acid-sensing by the abdominal vagus; in Costa A, Villalba E (eds): Horizons in Neuroscience Research. New York, Nova Science, 2010, vol 1, pp 367-377.

-22 Raybould HE, Glatzle J, Freeman SL, Whited K, Dracel N, Liou A, Bohan D: Detection of macronutrients in the intestinal wall. Auton Neurosci 2006;125:28-33.

23 Rozengurt E, Sternini C: Taste receptor signaling in the mammalian gut. Curr Opin Pharmacol 2007;7:557-562.

-24 Uneyama H, Niijima A, San Gabriel A, Torii $\mathrm{K}$ : Luminal amino acid sensing in the rat gastric mucosa. Am J Physiol Gastrointest Liver Physiol 2006;291:G1163-G1170.

-25 Uneyama H, Niijima A, Kitamura A, Torii K: Existence of NO-triggered vagal afferent activation in the rat gastric mucosa. Life Sci 2009;85:782-787.

-26 Fujita T, Kobayashi S, Yui R: Paraneuron concept and its current implications. Adv Biochem Psychopharmacol 1980;25:321325.

-27 Höfer D, Püschel B, Drenckhahn D: Taste receptor-like cells in the rat gut identified by expression of $\alpha$-gustducin. Proc Natl Acad Sci USA 1996;93:6631-6634.

28 Kitamura A, Sato W, Uneyama H, Torii K, Niijima A: Effects of intragastric infusion of inosine monophosphate and L-glutamate on vagal gastric afferent activity and subsequent autonomic reflexes. J Physiol Sci 2011;61: 65-71.

-29 Sharma KN, Nasset ES: Electrical activity in mesenteric nerves after perfusion of gut lumen. Am J Physiol 1962;202:725-730.

-30 Jeanningros R, Mei N: Données préliminaires sur la réponse des chémorécepteurs intestinaux acides aminés. Reprod Nutr Dev 1980;20:1615-1619.

- 31 Jeanningros R: Vagal unitary responses to intestinal amino acid infusions in the anesthetized cat: a putative signal for protein induced satiety. Physiol Behav 1982;28:9-21.

32 Niijima A, Torii K, Uneyama H: Role played by vagal chemical sensors in the hepato-portal region and duodeno-intestinal canal: an electrophysiological study. Chem Senses 2005;30(suppl 1):i178-i179.

-33 Eastwood C, Maubach K, Kirkup AJ, Grundy $\mathrm{D}$ : The role of endogenous cholecystokinin in the sensory transduction of luminal nutrient signals in the rat jejunum. Neurosci Lett 1998;254:145-148.

- 34 Schwartz GJ, Moran TH: Duodenal nutrient exposure elicits nutrient-specific gut motility and vagal afferent signals in rat. Am J Physiol 1998;274:R1236-R1242.
5 Raybould HE: Sensing of glucose in the gastrointestinal tract. Auton Neurosci 2007;133: 86-90.

36 Mei N: Intestinal chemosensitivity. Physiol Rev 1985;65:211-237.

37 Schwartz GJ: The role of gastrointestinal vagal afferents in the control of food intake: current prospects. Nutrition 2000;16:866873.

38 Tsurugizawa T, Kondoh T, Torii K: Forebrain activation induced by postoral nutritive substances in rats. Neuroreport 2008;19:11111115.

39 Tsurugizawa T, Uematsu A, Nakamura E, Hasumura M, Hirota M, Kondoh T, Uneyama $\mathrm{H}$, Torii K: Mechanisms of neural response to gastrointestinal nutritive stimuli: the gut-brain axis. Gastroenterology 2009; 137:262-273.

-40 Tsurugizawa T, Uematsu A, Uneyama H, Torii K: Blood oxygenation level-dependent response to intragastric load of corn oil emulsion in conscious rats. Neuroreport 2009;20: 1625-1629.

41 Ackroff K, Sclafani A: Flavor preferences conditioned by intragastric infusions of dilute polycose solutions. Physiol Behav 1994; 55:957-962.

42 Sclafani A: Fat and sugar flavor preference and acceptance in C57BL/6J and 129 mice: experience attenuates strain differences. Physiol Behav 2007;90:602-611.

43 Ackroff K, Sclafani A: Flavor preferences conditioned by intragastric infusion of ethanol in rats. Pharmacol Biochem Behav 2001; 68:327-338.

-44 Touzani K, Sclafani A: Lateral hypothalamic lesions impair flavour-nutrient and flavourtoxin trace learning in rats. Eur J Neurosci 2002;16:2425-2433.

45 Mark GP, Smith SE, Rada PV, Hoebel BG: An appetitively conditioned taste elicits a preferential increase in mesolimbic dopamine release. Pharmacol Biochem Behav 1994;48: 651-660.

46 Shibata R, Kameishi M, Kondoh T, Torii K: Bilateral dopaminergic lesions in the ventral tegmental area of rats influence sucrose intake, but not umami and amino acid intake. Physiol Behav 2009;96:667-674

47 Rozengurt E: Taste receptors in the gastrointestinal tract. I. Bitter taste receptors and $\alpha$-gustducin in the mammalian gut. Am J Physiol Gastrointest Liver Physiol 2006; 291:G171-G177.
48 Dyer J, Salmon KS, Zibrik L, Shirazi-Beechey SP: Expression of sweet taste receptors of the T1R family in the intestinal tract and enteroendocrine cells. Biochem Soc Trans 2005;33: 302-305.

49 Hirasawa A, Tsumaya K, Awaji T, Katsuma S, Adachi T, Yamada M, Sugimoto Y, Miyazaki S, Tsujimoto G: Free fatty acids regulate gut incretin glucagon-like peptide-1 secretion through GPR120. Nat Med 2005;11:90-94.

50 Itoh Y, Kawamata Y, Harada M, Kobayashi M, Fujii R, Fukusumi S, Ogi K, Hosoya M Tanaka Y, Uejima H, Tanaka H, Maruyama M, Satoh R, Okubo S, Kizawa H, Komatsu H, Matsumura F, Noguchi Y, Shinohara T, Hinuma S, Fujisawa Y, Fujino M: Free fatty acids regulate insulin secretion from pancreatic $\beta$ cells through GPR40. Nature 2003;422: 173-176.

51 Beardshall K, Frost G, Morarji Y, Domin J, Bloom SR, Calam J: Saturation of fat and cholecystokinin release: implications for pancreatic carcinogenesis. Lancet 1989;2: 1008-1010.

52 Viltart O, Sartor DM, Verberne AJ: Chemical stimulation of visceral afferents activates medullary neurones projecting to the central amygdala and periaqueductal grey. Brain Res Bull 2006;71:51-59.

53 Wang L, Martinez V, Barrachina MD, Tache Y: Fos expression in the brain induced by peripheral injection of CCK or leptin plus CCK in fasted lean mice. Brain Res 1998;791:157166.

-54 Baggio LL, Huang Q, Brown TJ, Drucker DJ: A recombinant human glucagon-like peptide (GLP)-1-albumin protein (albugon) mimics peptidergic activation of GLP-1 receptor-dependent pathways coupled with satiety, gastrointestinal motility, and glucose homeostasis. Diabetes 2004;53:2492-2500.

55 Mei N, Garnier L: Osmosensitive vagal receptors in the small intestine of the cat. J Auton Nerv Syst 1986;16:159-170.

-56 Randich A, Tyler WJ, Cox JE, Meller ST, Kelm GR, Bharaj SS: Responses of celiac and cervical vagal afferents to infusions of lipids in the jejunum or ileum of the rat. Am J Physiol Regul Integr Comp Physiol 2000; 278:R34-R43.

57 Niijima A, Meguid MM: An electrophysiological study on amino acid sensors in the hepato-portal system in the rat. Obes Res 1995;3(suppl 5):741S-745S.

58 Sclafani A, Lucas F: Abdominal vagotomy does not block carbohydrate-conditioned flavor preferences in rats. Physiol Behav 1996;60:447-453. 